a satisfactory endowment for a complete professorial body in connection with the University. In addition to the chairs which were already endowed they wanted endowments varying from $400 l$. to $600 l$. a year, which he did not think would be considered by any one as excessive, for fifteen chairs. The cost of such an endowment was, therefore, from $12,000 /$. to $20,000 \%$. If this work was to be carried on they must not expect too much from individuals. They might expect something from the great trade of Birmingham, a little from each member of the trade, if they would organise themselves for the purpose. The great inclustries when appealed to would see that they had a great duty in that matter, and would be glad to be represented in the work. They had already made some progress, and from two or three whom they had approached they might certainly expect the endowment of such a professorship. His duty that day was to put the question before them and ask them to accept the principle and give their good will and assistance in carrying it out.

\section{FRANCESCO BRIOSCHI}

BIOGRAPHICAL notices of this veteran Italian mathematician, who died on December 13 last, have been given in the Comptes rendus by M. Hermite, and by Cremona and Beltrami in the Annali di Matematica, the journal of which Brioschi was chief editor, and one of the founders in 1858 ; from these notices many of the following details of Brioschi's scientific work have been extracted.

This work covers about half a century in time of production, and ranges over the subjects of Analysis, Geometry, Higher Algebra, Differential Equations, Elliptic and Abelian Functions, Mechanics and Mathematical Physics.

Brioschi occupied himself at first with various dynamical questions, in continuation of the researches of Lagrange and Dirichlet. He next turned to the development of Gauss's analytic theory of surfaces, which had hitherto not attracted the attention it deserved. He also discussed the theory of the Correspondence of Poncelet's Polygons; as subsequently developed by Moutard and Halphen, this theory appears likely to provide the simplest analytical view of the Multiplication and Division of Elliptic Functions, at present engaging the atiention of Prof. H. Weber.

But the true bent of Brioschi's genius was found when he attacked the general theory of algebraical equations, being inspired by Hermite's discovery of the transcendental solution of the quintic equation, which has recently been summarised with developments in Klein's Lectures on the "Ikosahedron."

The history of the quintic equation throws a curious light upon the ways of a certain typical British school of mathematicians, who are accustomed to jog along in intellectual isolation, knowing and caring nothing for the advances made by others ; like "Rip van Winkles," as Clifford called them.

Working in this hermit-like way, Mr. Jerrard made the important discovery that it was possible by the solution of algebraical equations of an order not higher than the third, to reduce the general quintic equation to the trinomial form; but Klein has pointed out, in the "Ikosahedron," that all this had been done a hundred years ago, by the Swedish mathematician Bring, in I786.

Arguing by analogy, Mr. Jerrard, it is related, was firmly convinced that by the solution of a quartic, it would be possible to reduce the quintic to the binomial form, when the algebraical solution would be complete; and he died in happiness before having discovered his error, which a slight acquaintance with the work of Abel and Galois would have revealed.

The reduction by Hermite of the general quintic equation to the form of the Modular Equation of the Transformation of the Fifth Order of Elliptic Functions NO. I 473 , VOL. 57 ] suggested to Brioschi the examination of the corresponding equations of higher order ; and Brioschi's last communication was one to the Mathematical Congress at Zürich, 1897, on the particular case of the Transformation of the Eleventh Order.

Galois's statements " Les idées précipitamment émises," Halphen, "Fonctions elliptiques," iii. p. I24), which he did not live to demonstrate, that the Modular Equations of the Fifth, Seventh, and Eleventh Order have Resolvents of the same order, had long baffled analysts, and they did not receive universal acceptance till the appearance of the article in "Tortolini," 1853 , by Betti, Brioschi's co-editor, who succeeded in retracing Galois's line of argument; Betti's article being followed up by Hermite, in the Comptes rendus, 1859.

In his biographical memoir M. Hermite points out that Brioschi was the pioneer in another line of generalisation in the theory of algebraical equations, in his discovery of the solution of the general sextic equation, employing for that purpose the six even $\Theta$ functions, of two variables. The details of the development of this theory will afford plenty of employment to young mathematicians for some time to come.

In addition to his scientific labours, Brioschi found time to devote to public duties; he acted as an UnderSecretary of State, and was a Senator of the Upper House of the Italian Parliament; he was an organiser of the railway system of Italy, and he served on the International Committee of the Metric System.

$\mathrm{He}$ was a member of most of the Academies and Scientific Societies of Europe and America, and President of the Royal Academy of Lincei. The biographical notices by those who were personally acquainted with him speak highly of the respect and esteem which he inspired.

G.

\section{REV C. L. DODGSON.}

$A$ FORMIDABLE champion of Euclidean methods in the elementary teaching of geometry has just passed away after a short illness. The Rev. Charles Lutwidge Dodgson was born in 1832 at Daresbury in Cheshire ; and, after passing five years at Rugby School, matriculated in 1850 at Christ Church, Oxford, where he was appointed a student in 1852 , and graduated in 1854 with honours in both classics and mathematics. He was appointed Mathematical Lecturer in the College in I 855 , and retained that office till $I 8 \delta_{I}$; he further served the University as Mathematical Examiner in 1863, and Moderator in 1868 .

The mathematical subject in which he was most interested was the elementary teaching of geometry; of this he had a personal experience of twenty-six years. Without stint of labour he submitted to rigid logical analysis every text-book on the subject that came to his notice, undismayed by their surprising number, the result being the, amusing and, at the same time, deep "Euclid and his Modern Rivals," published in 1879 , in which he demonstrated the logical superiority of Euclid's method over all the others examined. The Appendices of this book are very valuable. A "Supplement" to it appeared in 1885 . In 1882 he edited Euclid, Books I. and II., with an introduction; and in 1888 he published "A New Theory of Parallels," in the third edition of which (1890) he simplified his fundamental axiom.

His other mathematical work comprises"A Syllabus of Plane Analytical Geometry" (1860), "Formulæe of Plain Trigonometry" (I86I), "An Elementary Treatise on Determinants" (1867), "Euclid, Book V., proved Algebraically" (1874), and "I'illow Problems" (1893). He invented a new method of evaluating determinants, which is published in the Proceedings of the Royal Society for I866, and also a method (which was published in NATURE) of easily determining the day of the 
week corresponding to any date. In October last he described in NATURE a brief method of dividing a given number by 9 or II; and a second paper on the same subject, which appears in our correspondence columns this week, probably represents his latest contribution to mathematics.

A characteristic of all his work was the absolute exactness of expression at which he aimed, so that his definitions and proofs should be logically perfect. This carried a certain severity into his work, since, as he has himself remarked, a semi-colloquial style is apt to be also semilogical, as nothing is more easy than to forget, in an argument which is interwoven with illustrative matter, what has, and what has not, been proved. It further tended to require the repetition of what might for exactness have to be a somewhat cumbrous periphrasis, to prevent which, therefore, he introduced a number of new terms and symbols; few of these have, however, been adopted into general use, though of the Jatter some are extremely expressive, and in his hands were of great value.

Mr. Dodgson's mind was essentially logical, in spite of the whimsical humour which has endeared "Lewis Carroll" to every boy and girl-nay, every adult-in the kingdom; and of late years he devoted a large part of his time to the study of the syllogistic methods of formal logic. In 1887 he published "The Game of Logic," and in 1896 "Symbolic Logic, Part I."

A shy and retiring man, he was to his friends a most charming companion, overflowing with the quaintest of humour, and one whose love for children was typical of himself, and whom to know was to love.

\section{NOTES.}

Mathematicians of all countries will be glad to hear that active steps are being taken to perpetuate the memory of the late Prof. J. J. Sylvester in a manner worthy of his reputation and in consonance with the spirit of his work. The movement was originated in this country by a few friends and admirers of the late Professor's, who decided upon founding a Sylvester Medal for the encouragement of mathematical research. The sympathy with the movement displayed by all the mathematicians who were communicated with, led the initiators to the conclusion that the most appropriate memorial would be one of international foundation, the more especially as Sylvester had a large number of friends and pupils in America, where indeed he may be said to have brought about a mathematical awakening through his connection with the Johns Hopkins University. The list of the International Committee which has now been issued, although only a preliminary one, comprises nearly the whole of the leading mathematicians of the world, besides many of the personal friends of the deceased mathematician and the representatives of the Universities of Oxford, Cambridge, London, Glasgow, Edinburgh and Dublin. From this list it might appear invidious to select names, but it is satisfactory to be able to call attention to the fact that it includes the Chancellor, High Steward and Counsel of the University of Cambridge, the Vice-Chancellor of the University of Oxford, the Provost of Trinity College, Dublin, the President of University College, London; with Lord Kelvin and Prof. P. G. Tait as representatives of the Universities of Glasgow and Edinburgh, and Prof. Henrici of the City and Guilds Institute. France is represented by Profs. Hermite, Poincaré, Camille Jordan, and Darboux; Germany by Profs. Schwarz, Klein, Fuchs, Gordan, and Lindemann ; Italy by the late Prof. Brioschi, and by Prof. Cremona; and Sweden by Prof. Mittag-Leffler. America has no less than fifteen names on the list, among them being President Gilman of the Johns Hopkins, Profs. Simon Newcomb, Willard Gibbs, and others representing the mathematical chairs of the various Universities. It is indeed certain that some movement of the kind would have been initiated in America if Sylvester's admirers in this country had not taken action. Now through Dr. Cyrus Adler, of the Smithsonian Institution, and Dr. G. Bruce Halsted, of Texas (a former pupil of Sylvester's), the Americans are working for the general scheme, and the two gentlemen named are acting as Treasurers for the United States. The general Treasurer of the fund is Lord Rothschild; Major P. A. MacMahon is acting as Hon Secretary, and Prof. Meldola, as a friend of the late Prof. Sylvester's, undertook the arduous work of preliminary organisation with the results which we are now making public. The executive Committee consists of Lord Rothschild, Major MacMahon, Prof. Forsyth, Prof. Greenhill, Prof. Henrici, and Prof. Meldola as Organising Secretary. We are informed that the subscriptions from private sources reached over $500 \mathrm{l}$. at the end of the year, and now exceed $600 l$, the American contributions not having yet been forwarded. It is proposed that the Medal shall be awarded triennially through the Council of the Royal Society, irrespective of nationality. Any friends of Sylvester's, or others who desire to participate in the movement, may send contribu. tions to Lord Rothschild, New Court, St. Swithin's Lane, E.C.

Mrs. Tyndali, the widow of Prof. Tyndall, has sent the following letter to Sir James Crichton-Browne, F.R.S., the Treasurer of the Royal Institution: "Dear Sir James,-As an expression of his attachment to the Institution, with which he was so long connected, and of his sympathy with its objects, my dear husband desired me (at such time as should be most convenient to myself) to present in his name to the Royal Institution $1000 l$. to be disposed of as the Board of Managers may see fit for the promotion of science. I have now the pleasure of remitting to you this sum. Yours faithfully, Louisa C. Tyndall." Sir James Crichton-Browne, in the course of his letter acknowledging this generous donation, remarks :- " The managers would, I am sure, desire to be guided by any wish of yours as to the application of the gift ; but, in the absence of any explicit directions, they will, I have no doubt, employ it in the promotion of that original scientific research in which your husband's vivid and penetrating intellect delighted to exercise itself. Revered as your late husband's memory is, and ever must be, in the Royal Institution, this posthumous mark of his solicitude for its welfare will, if possible, deepen the affectionate esteem in which he is held."

THE Council of the Royal Astronomical Society have awarded the Gold Medal of the Society for this year to Mr. W. F. Denning, "for his meteoric observations, his cometary discoveries, and other astronomical work." The award was confirmed on Friday last, and the medal will be given at the annual general meeting next month.

THE deaths are announced of Dr. Eduard Lindemann, scientific secretary in the observatory of Pulkova; and Dr. Oscar Stumpe, well known for his contributions on the motion of the solar system.

Dr. Maquenne, assistant at the Paris Muséum d'histoire naturelle, has been nominated professor of plant physiology, in succession to the late M. Georges Ville.

AT the February meeting of the Edinburgh Mathematical Society, a discussion on the proposal that, in the teaching of elementary geometry, Euclid's definition of proportion be abandoned, will be introduced by Prof. Gibson.

WE regret to see the announcement of the death of Lieut. Colonel C. Cooper-King, lecturer in natural science at the Staff College, Camberley. Colonel Cooper-King was a Royal Marine Artillery officer, and before joining the Staff College was an instructor at the Royal Military College, Sandhurst. 